\title{
RESIDENCIA HABITUAL DEL MENOR Y TRIBUNALES COMPETENTES PARA MODIFICAR UNA RESOLUCIÓN JUDICIAL SOBRE DERECHO DE VISITA. APLICACIÓN JURISPRUDENCIAL DE LOS ARTÍCULOS 8 Y 9 DEL REGLAMENTO (CE) 2201/2003
}

\author{
HABITUAL RESIDENCY OF THE MINOR AND COMPETENT \\ COURTS TO MODIFY A JUDICIAL RESOLUTION \\ ON THE RIGHT OF VISIT. JURISPRUDENTIAL APPLICATION \\ OF ARTICLES 8 AND 9 OF REGULATION (EC) 2201/2003
}

\author{
Diana Gluhaia \\ Profesora doctora \\ Universidad Internacional de la Rioja
}

Recibido: 14.01.2019 / Aceptado: 30.01.2019

DOI: https://doi.org/10.20318/cdt.2019.4646

\begin{abstract}
Resumen: En este Auto se cuestiona la competencia judicial internacional de los órganos jurisdiccionales españoles en materia de responsabilidad parental de una menor que cambió la residencia habitual a otro Estado miembro: Alemania. El artículo 9 del Reglamento (CE) n ${ }^{\circ}$ 2201/2003 es una excepción al criterio general de determinación de la competencia judicial internacional y sólo se activa cuando se cumplen todos los requisitos exigidos por esta norma. La Sala entendió que no se cumplían todas las condiciones, ya que no existía un pronunciamiento judicial previo respecto al derecho de visita que requiriese una modificación debido al traslado de la menor a otro Estado miembro, y que carece de sentido en este caso alterar una decisión judicial no existente.

Palabras clave: responsabilidad parental, competencia judicial internacional, residencia habitual del menor, competencia para modificar una resolución judicial sobre derecho de visita.

Abstract: His Order questions the international judicial competence of the Spanish courts in matters of parental responsibility of a minor who changed habitual residence to another Member State: Germany. Article 9 of Regulation (EC) $n^{\circ} 2201 / 2003$ is an exception to the general criterion of determination of international jurisdiction and is only activated when all the requirements demanded by this rule are met. The Chamber understood that all the conditions were not met, since there was no previous judicial ruling regarding the visiting right that required an amendment due to the transfer of the minor to another Member State, and that it makes no sense in this case to alter a decision non-existent judicial.

Keywords: parental responsibility, international jurisdiction, habitual residence of the minor, competence to modify a court ruling on visiting rights.
\end{abstract}

Sumario: I. Antecedentes de hecho del Auto 66/2018 de la Audiencia Provincial de las Islas Baleares. II. Fundamentos del fallo del Auto 66/2018 de la Audiencia Provincial de las Islas Baleares. III. Análisis de los artículos 8 y 9 del Reglamento (CE) nº 2201/2003. IV. Conclusiones. 


\section{Antecedentes de hecho del Auto 66/2018 de la Audiencia Provincial de las Islas Baleares}

1. Los hechos del supuesto vienen determinados por un recurso de apelación interpuesto por el padre de una hija menor, Don Camilo, contra el Auto del Juzgado de Primera Instancia número 5 de Palma de Mallorca dictado en fecha de 24 de noviembre de 2017, cuya parte dispositiva literalmente dice: "Se declara la falta de competencia de este juzgado para el conocimiento del presente procedimiento en atención a lo expuesto, debiendo presentarse la demanda ante los tribunales alemanes, que son los del lugar de residencia del menor".

2. En este caso, la hija menor de los litigantes abandonó España camino de Alemania el 8 de marzo de 2017. Don Camilo planteó una demanda de medidas paterno filiales el 5 de junio de 2017, solicitando "un convenio que regule las visitas de mi representado a la menor, así como especialmente la estancia de la misma con él en el periodo de vacaciones, en compensación por el tiempo que no la puede ver ya que la menor reside en Alemania y a mi representado le es imposible desplazarse a Alemania los fines de semana alternos (...)". El demandante basaba sus pretensiones en el artículo 9.1 del Reglamento (CE) n 2201/2003 del Consejo, de 27 de noviembre de 2003, relativo a la competencia, al reconocimiento y a la ejecución de resoluciones judiciales en materia matrimonial y de responsabilidad parental ${ }^{1}$. Para fundamentar sus pretensiones, Don Camilo aporta un certificado de empadronamiento de 11 de septiembre de 2017 de su hija menor.

\section{Fundamentos del fallo del Auto 66/2018 de la Audiencia Provincial de las Islas Baleares}

3. En este caso, se cuestiona la competencia judicial internacional de los tribunales españoles según el Reglamento (CE) n 2201/2003 en materia de responsabilidad parental en caso de cambio de la residencia habitual de la menor a otro Estado miembro: Alemania.

4. El Juzgado de Primera Instancia puso en conocimiento de las partes, mediante una diligencia de ordenación de 8 de junio de 2017, la cuestión sobre la competencia judicial internacional de los tribunales españoles. Entre la fecha de la presentación de la demanda y la diligencia de ordenación transcurrió un plazo de 3 días, por lo cual la Sala considera que no puede ser relevante la pretensión invocada por Don Camilo respecto a la tardanza del juzgado en resolver el asunto.

5. La juzgadora de primera instancia, en su resolución, desestimó la demanda de Don Camilo basándose en los artículos 8 y 9 del Reglamento, considerando que la hija menor residía en Alemania y por tratarse de la regulación de la guarda, custodia y alimentos que le afectaban directamente, el Juzgado español carecía de competencia judicial internacional para conocer del asunto, siendo competentes los órganos jurisdiccionales de Alemania.

6. La Sala de la Audiencia Provincial parte en su argumentación del Considerando 12 del Reglamento (CE) no 2201/2003 que dice lo siguiente: "Las normas de competencia que establece el presente Reglamento en materia de responsabilidad parental están concebidas en función del interés superior del menor, y en particular, en función del criterio de proximidad. Esto significa, por lo tanto, que son los órganos jurisdiccionales del Estado miembro en el cual el menor tiene su residencia habitual los que deben ser competentes en primer lugar, excepto en ciertos casos de cambio de residencia del menor o en caso de acuerdo entre los titulares de la responsabilidad parental".

7. El interés del menor es un concepto que desde el punto de vista del derecho internacional privado comporta la adopción de soluciones flexibles y disposiciones materialmente orientadas ${ }^{2}$. En efecto,

\footnotetext{
${ }^{1}$ Reglamento (CE) n $n^{\circ} 2201 / 2003$ del Consejo, de 27 de noviembre de 2003, relativo a la competencia, el reconocimiento y la ejecución de resoluciones judiciales en materia matrimonial y de responsabilidad parental, por el que se deroga el Reglamento (CE) no 1347/2000, DOUE, núm. 338, de 23 de diciembre de 2003, pp. 1 a 29.

2 A. Borrás Rodríguez, "El interés del menor como factor de progreso y unificación del Derecho internacional privado", Revista Jurídica de Catalunya, núm. 4, 1994, pp. 915-967.
} 
el "interés del menor" es un "concepto jurídico indeterminado" que escapa a una definición general y abstracta $^{3}$, y que necesita ser concretado para cada situación específica de cada niño en concreto ${ }^{4}$.

8. La Sala de la Audiencia Provincial de las Islas Baleares argumenta que las excepciones a la regla general prevista en el artículo 8.1 no se activan razonándose de la siguiente manera. Respecto a los artículos 10 (sustracción de menores) y 12 (prórroga de la competencia), señala que no son materialmente aplicables en este caso. En cuanto al artículo 9.1 del Reglamento (CE) n ${ }^{\circ}$ 2201/2003, la Sala tampoco acepta su aplicación, ya que como se trata de una excepción al principio general establecido en el artículo 8.1, debe aplicarse de una forma rigurosa, sin posibilidad de hacer interpretaciones extensivas y ya que no se dan algunas de las condiciones necesarias para su aplicación.

9. El padre, en su demanda de medidas paterno filiales, solicita el establecimiento por primera vez de un régimen de visitas con su hija menor. Esto quiere decir que no existía una resolución judicial anterior sobre el derecho de visitas susceptible de ser modificada.

10. La Sala argumenta que la excepción prevista en el artículo 9.1 mantiene la competencia del Estado miembro en el que tuvo la residencia habitual la menor durante los tres meses siguientes al cambio de residencia de ésta y exclusivamente para el caso de alteración de una regulación judicial previa del derecho de visitas. Es decir, para la modificación de una resolución judicial sobre el Derecho de visita dictada en dicho Estado miembro y siempre que el titular de tal derecho, con arreglo a la resolución judicial sobre esta cuestión, continúe residiendo habitualmente en el Estado miembro de la anterior residencia habitual del menor. La Sala de la Audiencia Provincial concluye que, en este supuesto, la competencia judicial internacional les corresponde a los órganos jurisdiccionales del Estado miembro en que la menor tiene su residencia habitual actual.

\section{Análisis de los artículos 8 y 9 del Reglamento (CE) n 2201/2003.}

11. La sección $2^{\text {a }}$ del capítulo II del Reglamento (CE) n $2201 / 2003$ regula la competencia de los órganos jurisdiccionales de un Estado miembro para conocer de las acciones relativas a la responsabilidad parental respecto de los menores y dentro de ella, la competencia para modificar las resoluciones que ya fueron dictadas por los órganos jurisdiccionales previamente.

12. La competencia judicial internacional en materia de responsabilidad parental se determina según el criterio principal y general previsto en el artículo 8.1, que es la residencia habitual del menor en el momento en el que se presenta la demanda. No obstante, esta norma no tiene un carácter absoluto, ya que establece excepciones en ciertos casos de cambio de residencia del menor o en caso de acuerdo entre los titulares de la responsabilidad parental ${ }^{5}$. Pero con independencia de estos casos puntuales, la "residencia habitual del menor" es el foro principal a la hora de determinar la competencia judicial internacional en materia de responsabilidad parental.

13. El Reglamento no contiene ninguna definición del concepto de "residencia habitual", por ello, es el Tribunal de Luxemburgo el que facilita varias precisiones sobre la interpretación de este concepto. No obstante, cabe mencionar que el Tribunal tampoco facilita una definición uniforme y global del concepto de residencia habitual que pudiera ser aplicado en todos los ámbitos del derecho europeo.

\footnotetext{
3 A.L Calvo Caravaca/ J. Carrascosa González, Derecho internacional privado, vol. II, Ed.: Comares, 17-ed., 2017, p. 534.

${ }^{4}$ A. Fernández PÉrez, "Aproximación al interés superior del menor en el derecho internacional privado español”, Boletín Mexicano de Derecho Comparado, vol.51 n.151 México Jan./Apr. 2018,

http://www.scielo.org.mx/scielo.php?script=sci_arttext\&pid=S0041-86332018000100107\&lng=en\&nrm=iso\&tlng=es\#fn37

${ }_{5}^{5}$ STJUE, de 15 de febrero de 2017, W y V, C-499/15, ECLI:EU:C:2017:118, apartado 55.
} 
14. El uso del adjetivo "habitual" solo indica cierta estabilidad o regularidad de la residencia ${ }^{6}$. El concepto de "residencia habitual" empleado en los artículos del Reglamento (CE) no 2201/2003 no realiza ninguna remisión expresa al Derecho de los Estados miembros. Por ello, este concepto debe ser interpretado de una forma autónoma y uniforme. Para precisar dicho concepto, debe tenerse en cuenta el contexto en el que se inserta el (la interpretación sistemática) y el objetivo que persigue la normativa lo (interpretación teleológica $)^{7}$. Habrá que tener en cuenta el Considerando 12 del Reglamento $(\mathrm{CE}) \mathrm{n}^{\mathrm{o}}$ 2201/2003 del cual se desprende claramente el objetivo de este Reglamento, en donde las normas de competencia que establece están concebidas en función del interés superior del menor, y en particular del criterio de proximidad.

15. El criterio de proximidad se corresponde con la residencia habitual del menor. De esta forma, el legislador europeo apreció que el órgano jurisdiccional que está geográficamente más próximo al menor es el competente para conocer del asunto. La proximidad geográfica del órgano jurisdiccional le convierte en el más idóneo para apreciar las medidas que han de adoptarse en interés superior del menor.

16. Será el órgano jurisdiccional nacional el que va a determinar el lugar en el que el menor tiene su residencia habitual. Como ha precisado el TJUE en numerosas ocasiones, para determinar la residencia habitual de un menor, además de la presencia física de este en un Estado miembro, es preciso que existan otros factores que revelen que dicha presencia no tiene en absoluto carácter temporal u ocasional ${ }^{8}$.

17. Además, la presencia física en el Estado miembro en el que el menor esté supuestamente integrado es un requisito necesariamente previo a la apreciación de la estabilidad de dicha presencia y que, por tanto, la «residencia habitual», en el sentido del Reglamento (CE) $n^{\circ} 2201 / 2003$, no puede fijarse en un Estado miembro en el que el menor nunca ha residido?.

18. Es menester mencionar el fallo de la STJUE ${ }^{10}$ respecto del concepto de "residencia habitual" empleado en el artículo 8.1, del Reglamento (CE) n 2201/2003. En efecto, sostiene que debe interpretarse en el sentido de que dicha residencia se corresponde con el lugar en el que el menor tiene "una cierta integración en un entorno social y familiar. A estos efectos deben considerarse, en particular, la duración, la regularidad, las condiciones y razones de la permanencia en el territorio de un Estado miembro y del traslado de la familia a dicho Estado, la nacionalidad del menor, el lugar y las condiciones de escolarización, los conocimientos lingüisticos, así como las relaciones familiares y sociales que el menor mantiene en el referido Estado. Es competencia de los órganos jurisdiccionales nacionales determinar la residencia habitual del menor teniendo en cuenta el conjunto de circunstancias de hecho particulares en cada caso". Podemos concluir que la residencia habitual del menor es el lugar que constituye el centro de los intereses del menor. Además, debe existir una cierta integración del menor en su entorno social y familiar y habrá que tener en cuenta el conjunto de las circunstancias ponderando las peculiaridades de cada caso en particular.

19. Respecto a la prueba presentada por Don Camilo, el certificado de empadronamiento de 11 de septiembre de 2017 de su hija menor no puede considerarse como prueba de su residencia habitual en España en los términos previstos por el TJUE. En este sentido, cabe destacar el Auto 30/2011 de la Audiencia Provincial de Valladolid, donde la Sala manifestó que en el certificado de empadronamiento presentado con la demanda no figuraba el empadronamiento de los menores en Valladolid, pero solo el

\footnotetext{
${ }^{6}$ STJUE de 22 de diciembre de 2010, Mercredi, C-497/10 PPU, EU:C:2010: 829, apartado 44.

7 A.L Calvo Caravaca/ J. Carrascosa González, Derecho internacional privado, vol. II, Ed.: Comares, 17-ed., 2017, p. 545.

${ }^{8}$ STJUE de 2 de abril de 2009, A, C-523/07, EU:C:2009:225, apartado 38; STJUE de 22 de diciembre de 2010, Mercredi, C-497/10 PPU, EU:C:2010:829, apartado 49; STJUE de 9 de octubre de 2014, C-376/14 PPU, EU:C:2014:2268, apartado 51; STJUE de 15 de febrero de 2017, W y V, C-499/15, EU:C:2017:118, apartado 60; STJUE de 8 de junio de 2017, OL, C-111/17 PPU, EU:C:2017:436, apartado 43, y STJUE de 28 de junio de 2018, HR, C-512/17, EU:C:2018:513, apartado 41.

${ }^{9}$ STJUE de 28 de junio de 2018, HR, C-512/17, EU:C:2018:513, apartado 53.

${ }^{10}$ STJUE de 2 de abril de 2009, A, C-523/07, EU:C:2009:225.
} 
del recurrente. No obstante, el obrante al folio 64 sí contenía el empadronamiento de los menores con fecha de 19 de abril de 2010 que era posterior en 4 días a la fecha de la presentación de la demanda. La Sala consideró que, al tiempo de presentación del asunto ante el Juzgado de Valladolid, éste ya carecía de competencia conforme al Reglamento (CE) no 2201/2003. La Sala de la Audiencia Provincial de Valladolid declaró que el simple certificado o empadronamiento de los menores no puede considerarse como prueba de su residencia habitual en España en los términos en que el Tribunal de Justica europeo ha construido dicho concepto, pues las pruebas aportadas demuestran que el arraigo e integración de los menores se encuentra en Francia donde han vivido normalmente, están escolarizados, son asistidos sanitariamente con regularidad desde su nacimiento, los progenitores tienen una propiedad en régimen compartido y donde incluso el recurrente sigue manteniendo y desarrollando su labor profesional ${ }^{11}$. Por ello, la mera inscripción del menor en registros públicos o padrón de un lugar no supone de forma automática que el menor tenga su residencia habitual en dicho lugar, sino que la misma se corresponde con el centro social de vida del menor.

20. Además, en virtud del artículo 16 del Reglamento, únicamente se considerará iniciado un procedimiento ante un órgano jurisdiccional cuando se presente el escrito de demanda o documento equivalente ante dicho órgano.

21. El artículo 9.1 del Reglamento (CE) no 2201/2003 establece: "Cuando un menor cambie legalmente de residencia de un Estado miembro a otro y adquiera una nueva residencia habitual en este último, los órganos jurisdiccionales del Estado miembro de la anterior residencia habitual del menor seguirán siendo competentes, como excepción al artículo 8, durante los tres meses siguientes al cambio de residencia, para modificar una resolución judicial sobre el derecho de visita dictada en dicho Estado miembro antes de que el menor hubiera cambiado de residencia, si el titular del derecho de visita con arreglo a la resolución judicial sobre el derecho de visita continúa residiendo habitualmente en el Estado miembro de la anterior residencia habitual del menor".

22. En efecto, en el caso de que se cambie de una forma lícita la residencia de la menor, los órganos jurisdiccionales de la residencia habitual anterior podrán prolongar su competencia durante los tres meses siguientes para modificar una resolución judicial sobre el derecho de visita. En esta línea, hay que subrayar que esta última norma solo se aplica para modificar una resolución judicial sobre el derecho de visita dictada por el Estado de la primera residencia, si el titular del derecho de visita con arreglo a la resolución judicial a modificar continúa residiendo en ese Estado ${ }^{12}$.

23. El artículo 9.2 establece que "El apartado 1 no se aplicará si el titular del derecho de visita considerado en el apartado 1 ha aceptado la competencia de los órganos jurisdiccionales del Estado miembro de la nueva residencia habitual del menor al participar en un procedimiento ante dichos órganos sin impugnar su competencia".

24. El principio de la "perpetuatio juridictionis" está limitado al cumplimiento de varias condiciones $^{13}$ : temporales, con un plazo de 3 meses, geográficas o espaciales, exigiendo que el titular del derecho de visita debe seguir residiendo en dicho Estado y subjetivos, puesto que no se aplica en el caso de que el titular del derecho de visita acepte la competencia del Estado miembro de la nueva residencia habitual y no haya realizado la impugnación ${ }^{14}$. En este sentido, cabe señalar que el periodo de tres meses debe calcularse a partir de la fecha en la que el menor fuese trasladado desde el Estado de origen. Dicha

\footnotetext{
${ }^{11}$ AAP de Valladolid, Sección 1a, Auto 30/2011 de 21 febrero de 2011, Rec. 484/2010.

${ }^{12}$ M.A. Gandía Sellens, "El Régimen Europeo de responsabilidad parental: su funcionamiento y las principales propuestas de cambio a raíz de la modificación del Reglamento Bruselas II bis", La Ley Derecho de familia, № 17, Primer trimestre de 2018, Editorial WoltersKluwer, La Ley, 1720/2018, p.1.

${ }^{13}$ A. QuiÑones EscÁMEZ, "Competencia judicial internacional en materia de responsabilidad parental y sustracción de menores en el Reglamento 2210/2003”, La Ley 16212/2008, p.3.

${ }^{14}$ STS, Sala Primera, de lo Civil, Sentencia 710/2015 de 16 diciembre, 2015, Rec. 2015/2013.
} 
fecha no debe confundirse con la fecha de la adquisición de la residencia habitual en el nuevo Estado miembro. Además, el artículo 9 se aplica sólo cuando el menor haya adquirido la residencia habitual en el nuevo Estado miembro en el periodo de tres meses. No hay que olvidar, además, que debe tratarse de un cambio lícito de residencia del menor de un Estado miembro a otro, en caso contrario entraría en juego el artículo 10 del Reglamento (CE) no 2201/2003.

25. La otra condición que requiere el artículo 9 y que es objeto del presente Auto es la existencia de una resolución judicial previa sobre el derecho de visita dictada en dicho Estado miembro que requiere una modificación debido al traslado de la menor a otro Estado miembro. Si no existe una previa resolución judicial sobre el derecho de visita no entra en juego la excepción prevista en el artículo 9.1 y la competencia será determinada según lo previsto en el artículo $8^{15}$. Un aspecto muy relevante, en este sentido, es que el artículo 9 sólo regula la competencia judicial internacional de los órganos jurisdiccionales cuando se deba alterar una resolución judicial previa sobre el derecho de visita. No caben otros asuntos relacionados con la responsabilidad parental, por ejemplo, el derecho de custodia. En fin, podemos señalar que la jurisprudencia exige la acumulación de estos requisitos ${ }^{16}$.

26. Por ello, la pretensión del demandante fue rechazada ya que al examinar el artículo 9.1 del Reglamento (CE) 2210/2003, la Sala entendió que no se cumplían todas las condiciones exigidas por el mismo. Concurrían la condición temporal, puesto que no habían transcurrido tres meses desde el cambio de residencia y la interposición de la demanda, y también las condiciones geográficas y subjetivos, pero faltaba una condición relevante que era la existencia de un pronunciamiento judicial previo respecto al derecho de visita que requiriese de una modificación debido al traslado de la menor a otro Estado miembro. Además, la Sala manifestó que carece de sentido, en este caso, alterar una decisión judicial que no existe. Es decir, la excepción prevista en el artículo 9.1 entra en juego únicamente cuando existe una decisión previa respecto al derecho de visita emitida por el tribunal del Estado miembro de origen antes de que la menor cambie de residencia a Alemania y además, se cumplan los otros requisitos exigidos.

\section{Conclusiones}

27. La competencia judicial internacional en materia de responsabilidad parental se determina según el criterio principal y general previsto en el artículo 8.1 que es la residencia habitual del menor en el momento en que se presenta la demanda. Las excepciones previstas al artículo 8.2 del Reglamento (CE) $n^{\circ} 2201 / 2003$ deben interpretarse de forma restrictiva y no extensiva.

28. El artículo 9 es una excepción al criterio general de determinación de la competencia judicial internacional en materia de responsabilidad parental y tiene como finalidad modificar una resolución judicial sobre el derecho de visita dictada en un Estado miembro antes de que la menor hubiera cambiado de residencia. Dicha excepción se activa cuando se cumplen los siguientes requisitos:

i. La demanda debe interponerse en el plazo de los tres meses siguientes al cambio de residencia.

ii. Existencia de una resolución judicial sobre el derecho de visita (no caben otras materias de responsabilidad parental) dictada en dicho Estado miembro antes de que el menor hubiera cambiado de residencia.

iii. Que se trate de un cambio legal de residencia del menor de un Estado miembro a otro.

iv. El menor haya obtenido la residencia habitual en el nuevo Estado miembro en el plazo de tres meses.

\footnotetext{
${ }^{15}$ Guide pratique pour l'application du nouveau règlement Bruxelles II (Règlement du Conseil (CE) n 2201/2003 du 27 novembre 2003 relatif à la compétence, la reconnaissance et l'exécution des décisions en matière matrimoniale et en matière de responsabilité parentale abrogeant le règlement (CE) n 1347/2000), pp. 13 y 14, http://jafbase.fr/docUE/GuidepratiqueBruxellesIIbis.pdf

${ }^{16}$ AAP de Madrid, Sección 22a, Auto 177/2007 de 3 Julio 2007, Rec. 506/2007.
} 
v. El titular del derecho de visita con arreglo a la resolución judicial previa debe seguir residiendo habitualmente en el Estado miembro de la anterior residencia habitual del menor.

vi. El titular no haya aceptado la competencia de los Tribunales de la nueva residencia del menor.

29. La excepción prevista en el artículo 9.1 que hace referencia al mantenimiento de la competencia del Estado miembro de la anterior residencia habitual del menor se activa sólo si se cumplen los citados requisitos de una forma acumulativa, en caso contrario se aplica la regla general que determina la competencia judicial internacional de los órganos jurisdiccionales del Estado miembro de residencia habitual del menor. Por tanto, la decisión estudiada es correcta ya que rechaza la pretensión del demandante al faltar una de las condiciones, como es la existencia de una resolución judicial previa al respecto. 